\title{
Identifying At-risk Freshmen and Providing Enhanced Advising Support Through Intrusive Academic Advising Interventions
}

\section{Mr. Jeremy C. Helm, Arizona State University}

Jeremy Helm is the Director of Academic Administration and Student Success in the Ira A. Fulton Schools of Engineering at Arizona State University. In this capacity, he oversees the schools' policies and processes related to academic standards; admission standards; curriculum implementation; advising services; first year programming and student support services.

\section{Ms. Tami Coronella, Arizona State University}

Tami Coronella is the Associate Director of Academic Administration and Student Success for the Ira A. Fulton Schools of Engineering. She has worked in advising and advising administration since 2000. Her academic career has been focused at Arizona State University, where she earned a B.S. in Management and an M.S. in Public Administration. She is currently a doctoral candidate for an Ed.D. in Educational Leadership and Innovation. Her interests include advisor development and assessment along with student retention and persistence.

\section{Mr. Tim Rooney, Arizona State University}




\title{
Identifying At-Risk Freshmen and Providing Enhanced Advising Support Through Intrusive Academic Advising Interventions
}

\begin{abstract}
This work in progress describes an effort to identify at-risk freshmen and provide enhanced advising support through intrusive academic advising interventions. In the report Rising Above the Gathering Storm: Energizing and Employing America for a Brighter Economic Future, the National Academy of Sciences, National Academy of Engineering, and Institute of Medicine of the National Academies identified the key roles innovation and competitiveness play in ensuring the prosperity of the United States (U.S.) economy within the world. Both innovation and competitiveness depend upon the knowledge capital of highly qualified and diverse college graduates to work in STEM fields. However, the U.S. education system is failing to produce sufficient college graduates to fulfill the emerging, rapidly growing job demands within STEM fields.
\end{abstract}

Our institution provides a breadth and depth of student support resources designed to improve freshman retention, yet retention rates of freshmen in engineering remained flat, year over year. New approaches for addressing retention are needed. Data was gathered on engineering students not retained to the university after one year from the past three years $(2014,2015$, and 2016) first-time freshman cohorts. Analysis of the data indicated certain academic and engagement measures were predictors of attrition. Furthermore, the analysis uncovered the opportunity to refine intrusive advising principles. Research on the impact of intrusive advising reflects a connection between successful academic advising and an increase in student retention and graduation rates. Through the requirement of mandatory advising for freshmen, advisors and students can collaboratively develop strategies for engagement with resources that will promote academic success. Theories and research focusing on academic advising approaches and student engagement guide advising discussions.

Alexander Astin [1], [2] developed the Theory of Student Involvement (TSI) model. With respect to academic advising effectiveness, Astin suggests "...that a particular curriculum, to achieve the effects intended, must elicit sufficient student effort and investment of energy to bring about the desired learning and development [1]". From TSI emerged the "I-E-O Model", which describes the influence of inputs and environment on outputs. The inputs include a student's high school GPA, SAT or ACT score, and his/her demographics. These inputs are useful in making admissions decisions. The environment describes the institutional policies, engagement opportunities, and student body. A student's involvement in purposeful and appropriate activities in his/her environment is a key factor in degree completion. The outputs are the institutional measures of retention and graduation rates. An academic advisor can serve as the communication channel for identifying appropriate and purposeful activities in which a student may engage. 
This study explores quantitative data on student behaviors, actions, and engagement. Data points include course enrollment or withdrawal, participation in certain programs (such as tutoring, orientation, pre-college activities), and receipt of academic warnings from faculty. Appropriate descriptive and inferential statistical analysis will be conducted during the semester in relation to the number of students enrolled from fall 2017 to spring 2018 as well as fall 2017 to fall 2018. Additionally, data from the students enrolled as freshmen in fall 2015 and fall 2016 will be considered.

Ultimately, the goal of the intrusive outreach is to realize a significant improvement in freshmen retention after one year as a result of intrusive academic advising interventions. Data from the previous and current freshman classes will be used to determine where intervention should occur in future terms.

\section{Problem Statement}

In the report Rising Above the Gathering Storm: Energizing and Employing America for a Brighter Economic Future, the National Academy of Sciences, National Academy of Engineering, and Institute of Medicine of the National Academies identified the key roles innovation and competitiveness play in ensuring the prosperity of the United States (U.S.) economy within the world. Both innovation and competitiveness depend upon the knowledge capital of highly qualified and diverse college graduates to work in STEM fields. However, the education system is failing to produce sufficient college graduates to fulfill the emerging, rapidly growing job demands within STEM fields. The purpose of this work in progress study is to explore the use of intrusive advising techniques with first-time full time freshmen identified as high risk for attrition based upon academic indicators. The goal was to increase the first-time freshman one-year retention rate. This study is in preliminary phases but expands upon previous research to further enhance retention.

\section{Purpose \& problem}

Recently, Arizona State University, a 4-year public institution, established two institution-wide goals: (a) improve one-year freshman retention rates to $90 \%$ and (b) improve 6-year graduation rates to $75 \%-80 \%$ and 25,000 graduates. The six-year graduation rate for a fall 2010 admitted freshman in the Fulton Schools of Engineering at Arizona State University was $66.4 \%$, below Arizona State University institution's average 6-year graduation rate of 67.1\%, and above the national average 6-year graduation rate of 59\%. One-year freshman retention rates for the Fulton Schools of Engineering reflected rates higher than the national average. The first-year freshman retention rate for students admitted in 2016 within the engineering program was $86.1 \%$. By comparison, $85.7 \%$ of all 2015 freshman were retained at Arizona State University after one year and nationally, retention of freshmen was $60 \%$ after one year (source: ASU institutional data). 
Table 1: One-year Freshman Engineering Retention Rate by Term

\begin{tabular}{|l|l|l|}
\hline Initial Admit Term & First Term (Spring) & Second Term (Fall) \\
\hline Fall 2012 & $95.60 \%$ & $88.10 \%$ \\
\hline Fall 2013 & $94.00 \%$ & $87.10 \%$ \\
\hline Fall 2014 & $95.50 \%$ & $86.80 \%$ \\
\hline Fall 2015 & $95.50 \%$ & $86.10 \%$ \\
\hline Fall 2016 & $94.90 \%$ & $86.40 \%$ \\
\hline Fall 2017 & $93.00 \%$ & TBD \\
\hline
\end{tabular}

As a result of this relatively static freshman retention rate, new approaches and initiatives were designed and introduced in an attempt to increase retention.

\section{Hypothesis}

Advising can support student involvement. As we utilize data, we can continue to refine intrusive advising outreach.

\section{Research Questions}

1. How do advisors obtain and use data on involvement to support their outreach?

2. How can data on involvement influence intrusive advising interventions?

\section{Relevant literature guiding the study}

Effective developmental advising is the use of interactive teaching, counseling, and administrative strategies to assist students to achieve specific learning, developmental, career, and life goals" [4]. Teaching strategies consider the role of the advisor in providing training and coaching on successful learning strategies. Counseling strategies focus on eliciting information from students to learn about any potential barriers to or conditions supporting learning. Finally, administrative strategies are the practices employed to cultivate advisor and student interactions. This paper considers the administrative strategies that were employed to foster advisor and student interactions thereby enabling the advisor to employ teaching and counseling strategies.

Researchers advocate for advisors to consider the type and depth of questions being asked by students during advising sessions while simultaneously evaluating and referring students to programming or resources to promote further student growth [4]. These resources might include workshops, referrals to services such as tutoring, career services, or lecture series [4]. This approach rests upon three key assumptions: (1) all students are the same, (2) all students will proactively seek out their advisor when help is needed, and (3) the advisor has a way to track or monitor student next steps.

Once meeting with a student, an advisor can employ one of two widely accepted practices, either developmental or prescriptive approaches. Developmental advising discussions focus on students' goals, challenges, and life advancements [8]. The advisor role in those discussions is to be a teacher, a guide as they consider policies, procedures, curriculum requirements, and engagement opportunities. Alternatively, prescriptive advising discussions are factual, often efficient, exchanges between the student and advisor. The advisor informs students of requirements, next steps, and expects the student to follow up the guidance [5]. Additionally, the student often initiates these discussions, versus the advisor initiating outreach.

The first semester of college for a student is most critical [13] as they are learning and adapting 
to a new environment. Furthermore, there is a host of interactions and discussions that Arizona State University has determined are essential in the first semester. These discussions include topics such as orienting the student to the university; guiding the student through selection of courses for the next semester; and supporting the student through any academic struggle. Institutions have typically developed resources to build engagement and support development, but they are often passive resources, requiring the student to choose to engage, yet those who would benefit most from engagement are least likely to engage [3].

Therefore, Arizona State University has turned to intrusive advising strategies, initiated by advisors [7]. Advising is intrusive when "deliberate structured intervention at the first indication of academic difficulty in order to motivate a student to seek help [7]" and is particularly useful with freshmen. Campbell [3] identified the assistance analytic models can offer for identifying those students most in need of intervention do benefit from targeted, intrusive advising. Further research identified how students who engaged with advisors via intrusive practices achieved higher GPAs and higher retention rates [11]. Once meeting with or speaking to the student, the advisor can choose to employ developmental or prescriptive approaches in their discussion.

In some circumstances, an advisor at Arizona State University can require the student to meet with him or her by placing an advising hold on the student's account. This hold places an electronic block on a student's ability to add or drop courses. Only an advisor within that student's department can remove the advising hold and usually does so after the student meets with the advisor.

Alternatively, an advisor may call or email a student and encourage the student to seek resources or support. The key component in this form of advising is the requirement of an interaction between the advisor and student which may include developmental or prescriptive advising techniques.

The use of technology and predictive systems are increasingly being employed within advising teams [6]. Academic analytics represent data collected by Arizona State University systems for retention, outcomes, and planning [6]. This type of data can then be used to improve retention efforts and then build retention efforts from the collected data. Junco [10] identified how data and technology can be applied within advising to influence the decision making process. Daughtry explored strategies for helping advisors manage their concerns with adoption and implementation for analytics in identifying students who need specific outreach and would benefit from intrusive advising interventions [6].

\section{Theoretical Framework}

Students have learned and grown through the college experience and that growth and learning has been explored through a variety of theoretical lenses [12]. One theoretical lens has been Alexander Astin's [1] Theory of Student Involvement (TSI). "The theory of student involvement argues that a particular curriculum, to achieve the effects intended, must elicit sufficient student effort and investment of energy to bring about the desired learning and development" [1]. Investment of energy and time were a measurement of a student's involvement defined as "the amount of physical and psychological energy that the student devotes to the academic experience" [1]. 
Examples of involvement included students' decisions to join a club, participate in tutoring, attend office hours with a faculty member, or live on campus [1]. There were multiple components of involvement. The first component measured involvement on a scale; a student could have been involved deeply with one activity and less deeply in another. A second component was that involvement was measured both quantitatively and qualitatively. For example, one could study the amount of time spent at the tutoring lab or the effectiveness of study habits. The third component was "the amount of student learning and personal development associated with any educational program is directly proportional to the quality and quantity of student involvement in that program" [1]. The fourth component focused on the effectiveness of the institution's student engagement policies and practices. These four components were combined to consider the involvement of a student in his/her college experience.

Quality indicators included retention and graduation rates. Astin [2] concluded that measurement of retention rates across institutions was not useful. Instead, he claimed institutions should conduct an internal comparison of a predicted retention rate to the actual retention rate. The predicted rate was based upon students' high school GPA, SAT Math and SAT Verbal scores. The product of the formula identified the predicted percentage of retention and was compared to the actual retention rate. Astin predicted [2], "institutions that are unusually adept at retaining students would be expected to have actual retention rates that substantially exceed their expected rates". Astin's research results indicated student inputs were only able to explain a portion of the variance between the predicted and actual retention rates [2].

The Input-Environment-Output (I-E-O) model was a framework developed by Astin to further assess student involvement [15]. Students must have taken the steps to engage in the environment for student learning to have occurred [12]. The model described the influence of inputs and environment on outputs [15]. The inputs included a student's high school GPA, SAT or ACT score, and his/her demographics. These inputs were used in making admissions decisions. The environment was comprised of the institutional policies, engagement opportunities, and student body. A student's involvement in purposeful and appropriate activities in his/her environment was key because outputs were a measure of student learning [12].

Decisions about input rates were determined at an institutional level. Programming and support services increase retention. Studies on retention by other researchers indicated the importance of student involvement [2]. "A great deal of empirical evidence suggests that the greater the student's level of involvement or engagement, the greater the chances of degree completion [2]". A student's time should be viewed as a valuable asset and constraint. "Administrators and faculty members must recognize that virtually every institutional policy and practice...can affect the way students spend their time and the amount of effort they devote to academic pursuits [1]".

The Cooperative Institutional Research Program (CIRP) has conducted an annual survey called the CIRP Freshman Survey (CIRP, n.d.). Astin [2] was a founding member of CIRP and he 
conducted a longitudinal analysis on students entering as first-time freshman in 1994. Of 56,818 students, four and six year input data and graduation rates were analyzed. Results indicated the inputs mattered and differences in retention rates across institutions ensued because their inputs were different. High school GPA was a stronger predictor than SAT score. Other important CIRP factors included years of science coursework completed, foreign language completion, time spent studying, and class attendance. Institutions with more selective admissions rates had higher persistence rates. This outcome was attributed to the peer environment of highly performing students and the perceptions of students because they were admitted [1], [2]. Astin concluded student involvement was shaped by the inputs and therefore, retention rates were a reflection of the students admitted.

Student learning in college has been considered to be a function of their time investment in purposeful activities and the creation of an environment that fostered and provided engagement opportunities [14]. Bowman and Seifert [14] conducted an analysis of over 3000 students attending one of 49 participating institutions in the Wabash National Study of Liberal Arts. The first portion of the research included a demographic survey. Those students who responded were then asked to complete an additional assessment. The researchers used the I-E-O model as a framework for assessing students' ability to identify their own learning in college. Qualitative and quantitative data were analyzed. The conclusions included the following: co-curricular experiences positively influenced learning and student development, peers were a significant influence on students' learning, it was a challenge for students to accurately describe their own learning, and students often perceived their own learning at a high level [14].

Strayhorn [15] applied the I-E-O model as a framework for assessing student engagement with advising activities. Strayhorn [15] conducted quantitative analysis of data included in the College Student Experiences Questionnaire (CSEQ) to identify potential activities (inputs) which yielded a measurable increase in student learning outcomes. Of the respondents to the CSEQ, 8,000 were randomly selected for analysis. Factor analysis was conducted on the CSEQ to consider input and output measures. Existing programs were analyzed. Strayhorn concluded student learning was the result of inputs and environment, as outlined by Astin's model. Findings indicated a positive correlation with interventions that enhanced student learning outcomes. Findings suggested institutions should consider programs that brought students together and supported learning such as peer study groups, peer mentors, and social outreach (Strayhorn [15]). The valued of academic advisors was a function of institutions that guided students to identifying these engagement opportunities.

\section{Context}

This work in progress study was conducted at Arizona State University. Arizona State University is the largest university in the country and the Fulton Schools of Engineering has the highest enrollment of Engineering schools in the U.S. Based upon the principles of intrusive, developmental advising, a program was designed to enhance the discussions and then by extension the relationship building occurring between the student and advisor. The program emerged from previous research and programmatic efforts. During previous cycles of action research and data analysis, certain academic indicators were related to student attrition. These included an early alert warning from an instructor, withdrawal from or failure in a course, and/or probationary status. Our initial analysis uncovered the need to refine 
identification of at-risk students and refine intrusive advising techniques used with those students. The research in this area suggests a correlation between successful academic advising and an increase in student retention and graduation rates.

At a presentation to the advising community, the Provost from Arizona State University stated: ...new tools to drive and do something different to manifest a different outcome, help them succeed, get them to succeed. We lose $7 \%$ at December. We have to help students earlier. [Analytic tools have been] designed to be a tool kit for advisors to intervene earlier.

During the same presentation, the Vice Provost stated how since 2007 "we have engaged primarily large scale targeted outreach broadly to all students, engaging students who want to be engaged". Furthermore, "advisors are expected to be innovative in improving retention and graduation rates with technologies that are dated with data that is stale". Additionally, the inclusion of new software systems, advisors can proactively engage students in meaningful ways at the most critical times, early in their academic careers.

With the introduction of campus-wide tools, the way advisors were informed of their students at- risk and in need of outreach has changed. In the past, outreach was managed via excel documents where advisors maintained a list of the students needing outreach and recorded the outcome of their advising discussions. These lists often stayed with the advisor and were not compiled for post-intervention assessment. In the fall of 2016, the Provost's Office at Arizona State University implemented the use of analytical tools to identify students who were at-risk for attrition as well as the use of a customer relationship management software package, Salesforce, to track and support intrusive advising.

Students are identified as they engage in certain academic behaviors related to attrition and a case is created in Salesforce. The "case" is loaded into an advisor's list of students needing outreach. The advisor can then track their conversations with the student as they work to provide developmental advising for the student and offer academic assistance and support. The behaviors which triggered advisor outreach included: withdrawal from courses critical for timely graduation; an early warning note from a faculty member due to behaviors such as poor performance or non-attendance; or a student response on a campus-wide survey indicating they would like to speak with an advisor. These cases, the outreach conducted, a summary of discussions, and the timing of the responses are all recorded within Salesforce.

\section{Intervention}

As this is action research, an intervention initiative was developed centrally to support the individual intrusive advising efforts of the advisors. Each university freshman is required to enroll in an entry level course, titled ASU 101 The ASU Experience. In the fall of 2017, a volunteer set of advisors actively attended four sessions of class for ASU 101. During these visits, the advisor completed intrusive advising outreach in-person for students who had cases in Salesforce. The case categories which prompted outreach included: an early alert from a faculty member in any of their courses; withdrawal from a course; non-enrollment for next term; or a student response on a survey requiring outreach. Advisors volunteered to support up to four sections of ASU 101 and were compensated an additional \$500 per 
session since participation resulted in their working extra hours during the week. A total of 20 advisors supported 63 sections of ASU 101.

Table 2: Sections of ASU 101 with or without Advisor Support and Number of Students

\begin{tabular}{|l|l|l|}
\hline Description of course & Number of Sections & Number of Students \\
\hline $\begin{array}{l}\text { Sections of ASU 101 with } \\
\text { enhanced advisor support }\end{array}$ & 63 & 910 \\
\hline $\begin{array}{l}\text { Sections of ASU 101 without } \\
\text { enhanced advisor support }\end{array}$ & 160 & 1632 \\
\hline
\end{tabular}

This intervention lasted from August 2017 to December 2017. The advisor was asked to attend four sessions of class (classes were scheduled for 50 minutes), once in August, September, October, and November. The first Monday of each month the advisor received an email indicating the recommended outreach. In August, they were encouraged to attend the first class and to begin getting to know the students enrolled in the course (class enrollment does not exceed 19 students per section for ASU 101). In September, the advisors were asked to speak to students about their acclimation to college and complete any early alert or survey response follow-up. In October, the advisors continued any earlyalert follow up and began discussing spring term enrollment with students. In November, they were requested to continue outreach to those students not yet enrolled. During the outreach, advisors were asked to encourage the student to schedule an appointment, engage with a resource, or attend an event which might support the student's development. Data continues to be collected throughout the first year of study.

Irrespective of this initiative, advisors visit every section of ASU 101 and conduct one 50minute class session. The goal of this session is to assist the students in selecting their courses for spring term and to begin developing an understanding of their curriculum for the next four years. This session is taught as a workshop, with each advisor working with multiple students to outline their course schedules. Those students enrolled in these sections of ASU 101, thus had a fifth advising interaction. Those students not enrolled in those sections of ASU 101 had only this one 50-minute class session to interact with their advisor. 


\section{Data and findings}

Table 3: Fall 2017 Admitted Students and their Spring 2018 Enrollment Status

\begin{tabular}{|l|l|l|}
\hline Enrollment Status & Number of Students & Percentage Enrolled \\
\hline Enrolled & 2542 & $93.25 \%$ \\
\hline Not Enrolled & 184 & $6.75 \%$ \\
\hline
\end{tabular}

Table 4: Fall 2017 Admitted Students and Spring 2018 Enrollment Status based on Registration in Advisor Supported ASU 101 Section (Pilot)

\begin{tabular}{|l|l|l|}
\hline Enrollment Status & $\begin{array}{l}\text { Not Enrolled in Pilot Section } \\
\text { of ASU 101 }\end{array}$ & $\begin{array}{l}\text { Enrolled in Pilot Section of } \\
\text { ASU 101 }\end{array}$ \\
\hline Enrolled in Spring & $92 \%(\mathrm{n}=1632)$ & $96 \%(\mathrm{n}=910)$ \\
\hline Not Enrolled in Spring & $8 \%(\mathrm{n}=143)$ & $4 \%(\mathrm{n}=41)$ \\
\hline
\end{tabular}

After considering retention rates into the second semester, salesforce case data were studied. Analysis of the data revealed a slight difference of 2.3 days in response time. This measure reflects the number of business days a case is open, suggesting the advisor and student have either not yet been able to speak, the student has been unresponsive, or the advisor has not yet initiated contact. An independent samples ttest was conducted amongst a random sampling of data and the findings indicated there was no difference in the means: $\mathrm{t}(163)=-3.51, \mathrm{p}=.159$.

Table 5: Average Time to Close Salseforce Cases based on Advisor Supported ASU 101 Sections

\begin{tabular}{|l|l|l|}
\hline Cases by section of ASU 101 & Number of Cases & $\begin{array}{l}\text { Average Time to Close Case } \\
\text { (days) }\end{array}$ \\
\hline $\begin{array}{l}\text { Sections of ASU 101 with } \\
\text { enhanced advisor support }\end{array}$ & 900 & 12.6 \\
\hline $\begin{array}{l}\text { Sections of ASU 101 without } \\
\text { enhanced advisor support }\end{array}$ & 1254 & 14.9 \\
\hline
\end{tabular}

Data on student engagement were also considered. This engagement looked at the engagement in academic success programs designed for freshman, which included small group tutoring sessions on math, chemistry, English, physics, and introduction to engineering courses. 
Table 6: Participation in Academic Success Programs based on Registration in Advisor Supported Section of ASU 101

\begin{tabular}{|l|l|l|}
\hline $\begin{array}{l}\text { Participation in engagement } \\
\text { activities by section of ASU 101 }\end{array}$ & Total Number of Students & $\begin{array}{l}\text { Participants in Academic } \\
\text { Success Programs }\end{array}$ \\
\hline $\begin{array}{l}\text { Sections of ASU 101 with } \\
\text { enhanced advisor support }\end{array}$ & 951 & 28 \\
\hline $\begin{array}{l}\text { Sections of ASU 101 without } \\
\text { enhanced advisor support }\end{array}$ & 1775 & 68 \\
\hline
\end{tabular}

\section{Discussion}

This limited available data suggests additional measures are needed to explore the research questions. This current data set is limited as the students have completed only one semester. Furthermore, data from advisors on the program is yet to be captured. Future research will specifically consider which populations of students may or may not be engaging in these academic success programs. In the future, the research team will examine which populations of students are or are not engaging and use qualitative data collection methods to learn why or why not students engage in the academic success programs. Additionally, participants in the academic success programs during fall 2017 will be closely monitored for their academic progress and retention into fall 2018.

\section{References}

[1] A. Astin, "Student involvement: A developmental theory for higher education," Journal of College Student Development, vol. 40, pp. 518-529, 1999.

[2] A. Astin, "Making sense out of degree completion rates," Journal of College Student Retention: Research, Theory and Practice, vol. 7, pp. 5-17, 2005.

[3] M. Campbell, The impacts of intrusive advising on the persistence of first-year science, technology, and mathematics students identified using a risk prediction instrument (Doctoral dissertation). Retrieved from ProQuest Theses \& Dissertations [UMI No. 3552312], 2013.

[4] L. Creamer and E. Creamer, "Practicing developmental advising: Theoretical contexts and functional applications." NACADA Journal, vol. 14(2), pp. 17-24, 2013.

[5] B. Crookston, "A developmental view of academic advising as teaching," NACADA Journal, Vol. 14(2) pp. 5-9. (Reprinted from 1972 Journal of College Student Personnel, 13, 12 17.), 1994.

[6] J. Daughtry, "An examination of advisor concerns in the era of academic analytics," 
Doctoral dissertation, retrieved from ProQuest Theses \& Dissertations [1968422458], 2017.

[7] R. Glennen and D. Baxley, "Reduction of attrition through intrusive advising," NASPA Journal, vol. 22(3), pp. 10-14, 1985.

[8] H. Himes, "Strengthening academic advising by developing a normative theory," NACADA Journal, vol. 34(1), pp. 5-15, 2014.

[9] M. Jeschke and J. Williams, "A comparison of intrusive and prescriptive advising of psychology majors at an urban comprehensive university," NACADA Journal, vol. 21(1/2), pp. 46-58, 2001.

[10] R. Junco, R. "Using emerging technologies to engage students and enhance their success," Academic Advising Today, retrieved from http://www.nacada.ksu.edu/Resources/Academic-Advising-Today/ViewArticles/UsingEmerging-Technologies-to-Engage-Students-and-Enhance-TheirSuccess.aspx, September $1,2010$.

[11] A Molina and R. Abelman, "Style over substance in interventions for at-risk students: The impact of intrusiveness," NACADA Journal, vol. 20(2), pp. 5-15, 2000.

[12] T. Pascarella and P. Terenzini, How college affects students. San Francisco, CA: JosseyBass, 2005.

[13] L. Rendón, "Validating culturally diverse students: Toward a new model of learning and student development," Innovative Higher Education, vol. 19(1), pp. 33-51, 1994.

[14] T. Seifert and N. Bowman, "Can College Students Accurately Assess What Affects Their Learning and Development?" Journal of College Student Development, vol. 52(3), 2011.

[15] T. Strayhorn, "How college students' engagement affects personal and social learning outcomes," Journal of College and Character, Arizona State University vol. 2, pp.1-16, 2008. 